\title{
Rethinking Climate-Smart Agriculture Adoption for Resilience-Building Among Smallholder Farmers: Gender-Sensitive Adoption Framework
}

\section{Sizwile Khoza, Dewald van Niekerk, and Livhuwani Nemakonde}

\section{Contents}

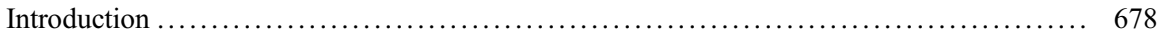

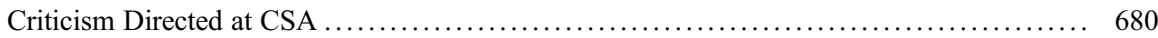

The Concept of CSA in a DRR Context .................................. 681

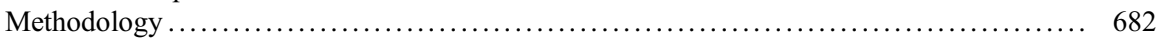

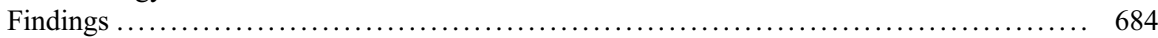

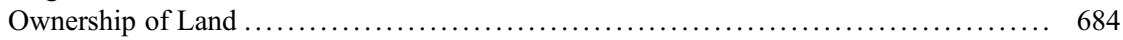

Participation in CSA Technology Development ................................. 684

CSA Options Available for Farmers ....................................... 685

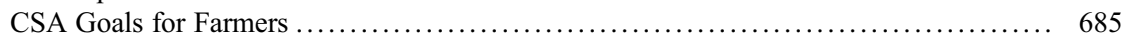

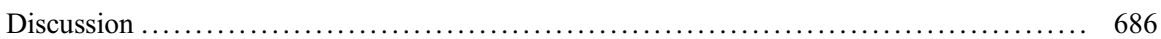

Gender-Equitable Resilience in CSA Adoption .............................. 686

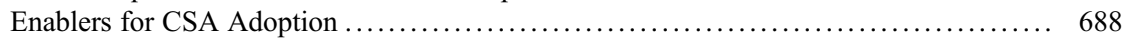

Strategies to Improve CSA Adoption .................................... 690

Gender-Equitable Resilience Capitals .................................... 691

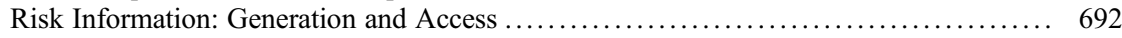

Risk-Informed Decision-Making ...................................... 693

Gender-Sensitive CSA Technology Development ............................ 693

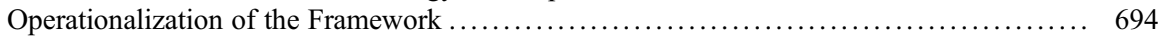

Key Lessons, Study Limitations, and Future Research Prospects for CSA _........... 695

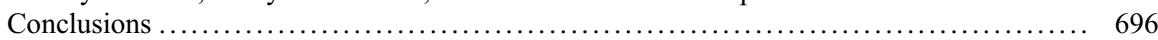

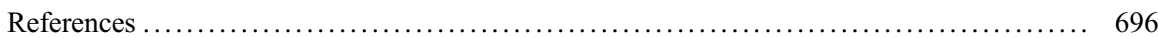

This chapter was previously published non-open access with exclusive rights reserved by the Publisher. It has been changed retrospectively to open access under a CC BY 4.0 license and the copyright holder is "The Author(s)". For further details, please see the license information at the end of the chapter.

S. Khoza $(\bowtie) \cdot$ D. van Niekerk $\cdot$ L. Nemakonde

Unit for Environmental Sciences and Management, African Centre for Disaster Studies, North-West University, Potchefstroom, South Africa

e-mail: sizwilenk@gmail.com; dewaldvn@acds.co.za; livhuwani.nemakonde@acds.co.za 


\section{Abstract}

This study identifies the need for holistic understanding of gender-differentiated climate-smart agriculture (CSA) adoption by smallholder farmers who are at the frontline of climate-related hazards and disasters in Africa. CSA adoption is predominantly informed by a parochial linear approach to farmers' decision-making processes. Resilience-building and adaptation, which forms the second pillar of CSA and can enhance understanding of the CSA adoption nuances at farmer level, often receives less attention in adoption investigations. To appreciate CSA adoption from a resilience perspective, this study focused on resilience-building based on the interlinkage between CSA and disaster risk reduction and applied a resilience perspective in a gendered approach to CSA adoption by smallholder farmers. Through primary data collected in an exploratory sequential mixed method design, the study presents a proposed normative gender-sensitive CSA adoption framework to guide CSA implementation strategies and policies. The framework is anchored in resilience thinking, and some of its key components include gender-sensitive CSA technology development, riskinformed decision-making by heterogeneous smallholder farmers, gender-sensitive enabling factors, resilience strategies, gender equitable and equal ownership, and control of and access to resilience capitals. The proposed framework can be used to improve CSA adoption by smallholder farmers by addressing gendered vulnerability and inequality that influence low adoption.

\section{Keywords}

Climate-smart agriculture $\cdot$ Disaster risk reduction $\cdot$ Gender $\cdot$ Adoption Resilience $\cdot$ Framework

\section{Introduction}

Climate change threatens the achievement of sustainable development, undeniably presenting complex developmental challenges in less developed regions. The impetus is to find solutions to the dilemmas that disasters related to climate change present, especially in regions such as Southern Africa, which are categorized as climate change hotspots (Müller et al. 2014). In recent agricultural seasons, Southern Africa has faced devastating and unprecedented climate change-related disasters, often resulting in Member States declaring a state of disaster. Some climate-related disasters affect only one country, such as the floods in Malawi in the 2014-2015 agricultural season that caused the country to declare a state of disaster due to floods (Murray et al. 2016). Others transcend national boundaries, for example, the El Niño-Southern Oscillation-induced drought of 2015-2016 that caused Eswatini, Lesotho, Malawi, Namibia, and Zimbabwe to declare state of drought emergency (Nhamo et al. 2019). Other examples include the fall armyworm Spodoptera frugiperda infestation of 2017-2018 and cyclones Idai and Kenneth in the 
2018-2019 season. The result of these disasters is that the food security, poverty alleviation, and sustainable development ambitions of individual countries and the affected regions are hampered (Lipper et al. 2018). One of the chief concerns is the effect of climate-related disasters on smallholder farming, which in most developing countries is estimated to constitute at least $70 \%$ of the population, with the agriculture sector contributing at least a third of gross domestic product (Diao et al. 2010).

Consequently, current development discourse in Africa is concerned with exploring resilience-building strategies for smallholder farming households so that they may become resilient in the face of climate-related disasters (Speranza et al. 2014; Lipper et al. 2018). With each climate-related disaster, there is a growing need to change from conventional agricultural farming toward new, unfamiliar, and uncommon farming technologies perceived to contribute toward resilience-building. It is for this reason that climate-smart agriculture (CSA) has gained prominence as a possible panacea to the developmental challenges presented by climate change, specifically in relation to smallholder farming in Africa (Arslan et al. 2018). CSA recognizes that climate change amplifies developmental challenges, hence its conceptualization based on three pillars, viz., (1) improved food and agricultural productivity, (2) resilience-building and adaptation, and (3) mitigation through the reduction of greenhouse gas emissions from agricultural activities (Asfaw et al. 2015; Chandra et al. 2017a). CSA is a livelihood-oriented integration of the triple wins of sustainable intensification, resilience-building, and climate mitigation (Taylor 2018). The adoption of CSA technologies and strategies provides one option for resilience-building. Consequently, there is growing focus on adoption of CSA technologies by smallholder farmers (Kpadonou et al. 2017; Nyasimi et al. 2017), although there are still some shortcomings in the understanding of CSA adoption. This chapter seeks to offer an in-depth understanding of the tensions between gender inequality and CSA adoption and of the existing limitations to resilience-building through CSA. The research departed from a resilience perspective applied on the CSA pillar that seeks to build resilience and promote the adaptation of smallholder farmers. It was conducted in two regions sharing almost similar disaster profiles, namely, Malawi and Zambia.

Findings show that low CSA adoption can be attributed to gender disparities in ownership of resilience capitals, inadequate provision for equal participation of smallholder farmers in CSA technology development, a lack of diverse CSA options that farmers could adopt, and the failure to sustain household food security, income generation, and improved quality of life through CSA. This chapter accentuates that increasing climate risk compels an exploration of measures to address these shortcomings of CSA. Furthermore, the paper emphasizes heightened need to pursue alternative gender-sensitive pathways that may help address gender disparities. Such disparities in smallholder farming societies continue to be a barrier not only to CSA adoption but also to resilience-building in the face of climate change. In pursuit of alternative approaches to addressing barriers to CSA adoption and increasing its uptake by smallholder farmers, this chapter presents a normative gender-sensitive CSA adoption framework that can be adapted and used in developing regions, ultimately contributing to resilience-building. 


\section{Criticism Directed at CSA}

The conceptualization of CSA envisions that humanity could address some of its developmental challenges, such as the negative effects of climate change, population growth, and the corresponding increases in food demand, poverty, and sustainable development (Williams et al. 2015). Unfortunately, despite its positive attributes, CSA has also been met with some skepticism that cannot be ignored in a gendered approach to CSA adoption. The main criticism is insufficient consideration of power relations and inequalities (Chandra et al. 2017b). While Taylor (2018) considers power disparities at a global level between countries of the North and the South, this study considers these aspects at a farmer level. Further dissentions over CSA emanate from its failure to promote participation of local communities, with technologies and research dominantly unidirectional and top-down (Chandra et al. 2017a). Other scholars caution that when CSA fails to pay attention to social issues, its implementation may actually magnify preexisting social imbalances such as gender inequality (Murray et al. 2016; Collins 2017). When considered within the context of the pivotal role women play in smallholder farming, current CSA scholarship has insufficiencies when it comes to the appreciation of the gender dimensions in the CSA adoption decision-making process. Yet, for many African societies, the gender composition in the smallholder farming sector validates the relevance of gender as an investigative element.

Previous work by Khoza et al. (2019) shows that underlying gender inequality, patriarchy, and other social imbalances manifest as gender-differentiated, sociocultural, sociopsychological, and gendered vulnerability drivers that shape decisions on whether to adopt, dis-adopt, or not adopt CSA technologies. This emanates from a focus on CSA as solving the dilemma of climate change through technical fixes to increase food production. The provision of technological solutions for resilience requires consideration of their social implications, the absence of which has resulted in growing concern over the observed adoption paradox. Failure to address the underlying gender inequalities and vulnerabilities may have ramifications for resilience-building for smallholder farmers. Additionally, an existing understanding of CSA adoption is framed within a simplistic linear approach, which is insufficient when gender and resilience-building dimensions are brought into consideration. Thus, this study was conducted with the aim to explore the application of a resilience perspective to CSA to address the underlying gender inequality and gendered vulnerability in order to improve CSA adoption by diverse men and women smallholder farmers.

The shortcomings of CSA have also been linked to the issue of a conceptual misnomer, arising from a general conceptualization of CSA that includes policies, technologies, and practices at farmer, landscape, and ecosystem levels (Lipper et al. 2014). While some literature labels CSA as an already compromised concept pushing a hegemonic agenda for the developed countries (Taylor 2018), the concept has the potential to address some of the challenges African societies face with climate change. Having considered the concerns, this study situates CSA adoption assessment at a farmer level and with a deliberate focus on technologies and practices that farmers have to adopt. Some scholars highlight the need for alternative 
frameworks to address the shortcomings of CSA (Taylor 2018; Glover et al. 2019). This gives currency to the application of resilience thinking in CSA adoption, and a reconnaissance of CSA that leverages on its relationship with disaster risk reduction (DRR) can help address some of the highlighted shortcomings.

\section{The Concept of CSA in a DRR Context}

The second pillar of CSA is "resilience-building and adaptation," which underpins the interconnectedness of CSA and DRR (FAO 2013). This relationship paves the way for the application of a DRR lens to CSA in order to explore opportunities for improving CSA adoption by smallholder farmers. The climate-related risks and disasters affecting smallholder farming as already outlined in the introduction of this chapter give credence to such an approach. Moreover, at a farmer level, the demarcations between adaptation, resilience-building, and DRR are indistinct, as farmers are more concerned with surviving each disaster event.

A DRR approach to CSA draws attention to issues of vulnerability reduction, while CSA implementation in smallholder farming provides a vehicle to deliver both risk reduction and adaptation simultaneously (FAO 2013). A DRR approach to CSA could help resolve some of the shortcomings of CSA as highlighted in the preceding section. Greater strides have been made in DRR than in CSA, for example, in terms of the appreciation of resilience-building, indigenous knowledge systems, and the application of socio-ecological system concept to understand resilience-building and communitybased participation (FAO 2013; Coetzee et al. 2016). Therefore, CSA could draw from progress made in DRR this far as a way of resolving the adoption challenges. Unfortunately, there has been minimal scholarly interrogation of CSA from a DRR perspective. Yet, at a time when increased climate risk threatens to wipe out the development gains made in agriculture so far, such a consolidated approach could better cross-examine CSA adoption. Furthermore, the relationship of DRR and resilience provides basis to interrogate CSA adoption from a disaster resilience perspective.

Disaster resilience is framed as an ability, where a system and its units are able to anticipate, absorb, accommodate, and recover from a disturbance by bouncing back or bouncing forward timeously and efficiently (Manyena et al. 2011). The system and its units may have the ability to change without loss of basic structure and functions, or self-organize, attaining incremental capacity to learn, adapt, and change through absorptive, adaptive, or transformative capacities (Béné et al. 2016). When smallholder farmers make decisions to adopt CSA technologies and practices, that is essentially indicative of their aspirations to be resilient to climate vagaries. Resilience of a system or its units, which in this study were individual farming households in a farming system, is better appreciated by considering resilience principles. This includes maintenance of redundancy and diversity, management of intra-system connectivity, feedbacks, promotion of social learning, participation and inclusion, embracing polycentricity, and understanding that agricultural systems are complex adaptive systems (Carpenter et al. 2012; Coetzee et al. 2016). Therefore, in assessing CSA adoption challenges from a resilience perspective, we argue that these 
resilience principles can be applied to assess barriers to CSA adoption and may help identify required improvements to build the resilience of farming households and communities.

Absorptive resilience is when households are able to contend with the negative effects of climate disasters through persistent coping and resistance, without any distinct changes to function or structure (Bennett et al. 2014), for example, when households cope with a drought through humanitarian interventions such as food aid distribution. Adaptive resilience is when the agricultural system or its units have the ability to learn from acquired or experiential knowledge and to make adjustments in response to disasters (Walker et al. 2004). In adaptive resilience, the aim is to make adjustments for continued functioning within a household or system. Transformative resilience refers to the capacity for change in structure and function of the system or households owing to disturbance. Transformation is more concerned with changes made in behaviors, cultural ethos, stereotypes, institutions, and policy direction (Walker et al. 2004). Thus, transformation depends on interrogation of the status quo and advocating for pragmatic changes in structure or function to be instituted. Adaptation and transformation are long-term and essential dimensions of resilience from a development standpoint. It is important to bear in mind that the three dimensions should not be pursued separately in linear fashion. It is important to harness the existing synergies among them (Béné et al. 2016).

Accordingly, for the majority at-risk rural smallholder farmers, CSA offers a pragmatic relevant conduit to pursue resilience. The assorted CSA options (see Table 1) contribute or have the potential to contribute to the three resilience dimensions, so it is worth mentioning that CSA implementation and policies should not elevate any one dimension and subordinate the others. Rather, in building on the synergistic relationships of absorption, adaptation, and transformation, CSA can help smallholder farmers and their systems become resilient.

In the context of smallholder farming in developing regions where CSA is promoted, it is key to recognize the heterogeneity of the farmers (Khoza et al. 2019).

The diversity among smallholder farmers draws attention to existing inequalities that relate to vulnerability and shape power, agency, ownership and control of resources, decision-making, and participation within farming systems (Ensor et al. 2018). This magnifies the need for resilience-building in CSA to pay attention to the skewed landscape within which CSA adoption decisions have to be made by different farmers. Ultimately, this mandates that over and above absorptive and adaptive resilience, transformation is required in CSA. This compels the interrogation of existing social imbalances that determine whether a smallholder farmer will adopt, dis-adopt, or not adopt CSA.

\section{Methodology}

An exploratory sequential mixed method design (Teddlie and Tashakkori 2009) was applied in Chikwawa, Malawi, and Gwembe, Zambia, to gather empirical data at a local level where smallholder farmers interface with climate-related disasters and 
Table 1 Climate-smart agriculture options

\begin{tabular}{|c|c|}
\hline CSA options & Examples \\
\hline \multirow[t]{7}{*}{ Crop management } & Intercropping \\
\hline & Crop rotation \\
\hline & Crop diversification \\
\hline & Improved seed varieties \\
\hline & Value chains and marketing \\
\hline & Improved postharvest storage \\
\hline & Agro-processing \\
\hline \multirow[t]{5}{*}{ Livestock management } & Fodder crops \\
\hline & Feedlots \\
\hline & Improved breed \\
\hline & Rotational grazing \\
\hline & Grassland restoration and conservation \\
\hline \multirow[t]{3}{*}{ Soil and water management } & Basin/mechanized conservation farming \\
\hline & Solar-powered irrigation \\
\hline & Rehabilitation of degraded landscapes \\
\hline \multirow[t]{4}{*}{ Agroforestry } & Woodlots \\
\hline & Fruit trees \\
\hline & Nitrogen-fixing trees \\
\hline & Multipurpose trees \\
\hline \multirow[t]{2}{*}{ Integrated food-energy systems } & Biogas stoves \\
\hline & Energy-saving stoves \\
\hline \multirow[t]{3}{*}{ Infrastructure } & Roads \\
\hline & Housing \\
\hline & Mobile network \\
\hline Access to climate information & ICT platforms/information hubs \\
\hline \multirow[t]{2}{*}{ Fisheries } & Aquaculture \\
\hline & Capture fisheries \\
\hline
\end{tabular}

Adapted from FAO (2013)

where resilience-building is essential. The study was conducted between 2017 and 2019, with data collection in February and March 2018. The initial phase entailed qualitative data collection through semi-structured face-to-face interviews from purposively selected key informants at district level and focus group discussions (FGDs) at ward level. A total of 16 interviews and 6 FGDs were conducted (3 in each country: men only, women only, and mixed men and women). Thematic qualitative data analysis informed the design of an instrument used in quantitative cross-sectional data collection. In the quantitative cross-sectional survey, a total of 102 smallholder farmers were interviewed, 51 from each study site. The crosssectional survey served to explore the generalizability of the themes established from the qualitative findings. In order to capture the perspectives and contexts of the gender dimensions in CSA adoption, the study placed emphasis on qualitative findings. This is in line with the methodological provisions of a mixed method 
research design (Teddlie and Tashakkori 2009). The quantitative data was analyzed with SPSS version 26 for descriptive statistics that established the distribution and trends.

\section{Findings}

\section{Ownership of Land}

The findings revealed that in Chikwawa, the average land owned by men household heads was 1.4 ha, while for women, it was 0.7 ha. In Gwembe, $40 \%$ of womenheaded households who indicated they rented land did so for CSA purposes. While men household heads generally rented land in addition to what they owned, the women rented land because they were landless. Land ownership by women in Africa is a contentious issue (Doss et al. 2015), and these findings call for renewed effort to address the issue. Land ownership influences the adoption of agricultural technologies and practices; therefore, if CSA is to contribute to resilience-building, there is a need for equal distribution of land as a starting point toward equitable resilience (Matin et al. 2018).

\section{Participation in CSA Technology Development}

The qualitative findings established that CSA technology development occurred in a top-down manner, with smallholder farmers not engaged in technology development as they are generally considered as recipients "who receive your technology you have developed for them" (NGO respondent, Chikwawa). In both study sites, field days and demonstration plots were identified as opportunities for farmer participation in technology development. However, respondents acknowledged that even these events were top-down as they mainly showcased technologies that had been developed for the farmer, and technologies developed with the farmers' involvement were rare, if any. Currently, no mixed approach to CSA technology development that comprises technologies developed for and with the farmers is being considered. This may be due to the perception that farmers are technology recipients, as reflected by some interviewees: "they cannot contribute anything in technology development... what do farmers know that they can contribute in CSA?" (Government Department Respondent, Gwembe).

These sentiments were corroborated by quantitative findings that established that there was minimal participation among farmers in technology development irrespective of gender. In Chikwawa, $25 \%$ of the households, with over $70 \%$ of these being male household heads, stated that they had been involved in meetings when conservation farming and irrigation schemes were first brought to their communities. In Gwembe, $11 \%$ of the farmers acknowledged participation in similar meetings. At both study sites, those who participated in meetings went on to become adopters as they benefited from the respective CSA projects. 
However, this is insufficient as participation should also include problem identification, evaluation of options, and eventual selection of technologies that farmers know will address their problems. This would leave room for the consideration of indigenous knowledge systems, which can also be considered as alternatives to solve the problems farmers face. For example, in Chikwawa, farmers shared how they used a fish broth to control the fall armyworm before pesticides were available. Scientific research could be incorporated to explore how indigenous knowledge can be harnessed in CSA.

\section{CSA Options Available for Farmers}

The qualitative findings established that conservation farming was the major form of CSA that farmers have adopted, and confirmation from quantitative findings revealed that $100 \%$ of farmers practicing CSA at both sites stated that they used improved seed varieties (ISVs) and soil moisture conservation techniques. At both study sites, less than $40 \%$ of sampled households were engaged in more than one form of CSA. In Chikwawa, other forms of CSA included small-scale irrigation schemes, while in Gwembe, a new aquaculture project was at inception stage at the time of data collection. In Gwembe, less than $20 \%$ of interviewed farmers had also been previously involved in improved livestock breed projects. However, the qualitative findings showed that there were concerns that conservation farming alone was insufficient in addressing farmers' needs as explained by practitioners:

...we know that crop production is always vulnerable, we also need to bring in livestock for the farmers, to help them when crops fail. . .especially goats which they can sell when crops fail. (Respondent from Government Department, Chikwawa)

The quantitative findings showed that livestock ownership differed between male and female heads of households. At both sites, married men owned the most cattle, with average cattle ownership in Chikwawa being two heads, while in Gwembe, it was eight. More female household heads owned cattle in Gwembe than in Chikwawa, $16 \%$ and $7 \%$, respectively. When these trends are viewed from an intersectionality perspective, intersection of gender with education and wealth status can be noted as the women who owned cattle in Gwembe were predominantly retired professionals who were categorized as better-off in the community wealth rankings.

\section{CSA Goals for Farmers}

In Chikwawa, qualitative findings established that the intended CSA outcomes of improved agricultural productivity and resilience-building were not being achieved by means of the CSA options available to farmers. Evidence of these shortcomings of CSA was linked to humanitarian food assistance. Qualitative findings indicated that there was no major difference in terms of food security between CSA farmers 
and those who were not involved in any form of CSA because "we see it when it comes to food aid, they all need assistance because they will be all food insecure" (Respondent from Government Department, Chikwawa). More concerning were sentiments from non-adopters who indicated a lack of motivation to adopt available CSA options because "we are all the same, CSA does not make them any better than us" (Discussants in mixed gender FGD, Chikwawa). These findings were confirmed by the quantitative survey where $100 \%$ of farmers who adopted conservation farming also reiterated that they benefited from food aid each year because of low crop yields. Farmers using ISVs raised concerns about their susceptibility to the fall armyworm, claiming that their traditional open-pollinated varieties (OPVs) were better resistant.

In Gwembe, a different scenario emerged when assessing whether CSA options were able to contribute to food security and resilience-building. Qualitative findings established that while yields increased through conservation farming, there were postharvest crop losses as farmers could not sell their surplus anywhere. Quantitative findings confirmed these sentiments as $100 \%$ of the farmers who were practicing conservation farming techniques were utilizing less than half of their arable land for CSA to "avoid high yields that they would still lose through spoilage," as farmers concurred during household survey in Gwembe.

\section{Discussion}

\section{Gender-Equitable Resilience in CSA Adoption}

The findings presented in this chapter show that men and women farmers may not be realizing benefits of the CSA activities they are involved in. Findings further show that currently, CSA is not contributing toward the resilience of farmers as they are still prone to food insecurity, often relying on food aid to see them through to the next season. This creates a dependency syndrome and demotivation farmers in CSA adoption. Moreover, dominance of conservation farming leaves farmers vulnerable to climate hazards that have a negative effect on crop production. Findings illuminate the insufficiencies of current CSA and gaps that continue to hinder CSA adoption, especially among women farmers. This chapter accentuates that a resilience framing of CSA leaves room for broader consideration of the decision-making context within which smallholder farmers live. On that basis, a normative gendersensitive CSA adoption model (Fig. 1) is proposed.

The aim of the framework is to provide a normative approach to improve CSA adoption, especially by diverse women smallholder farmers in developing regions, considering their central role in farming activities. The framework is conceptualized from a resilience viewpoint, enabling a more holistic approach to the issues that may enhance decision-making by different groups of farmers, especially diverse women smallholder farmers. There is a need for gender transformation at various CSA implementation levels, starting at household level up to national and global levels. Transformation requires various strategies and enablers to be put in place to create 


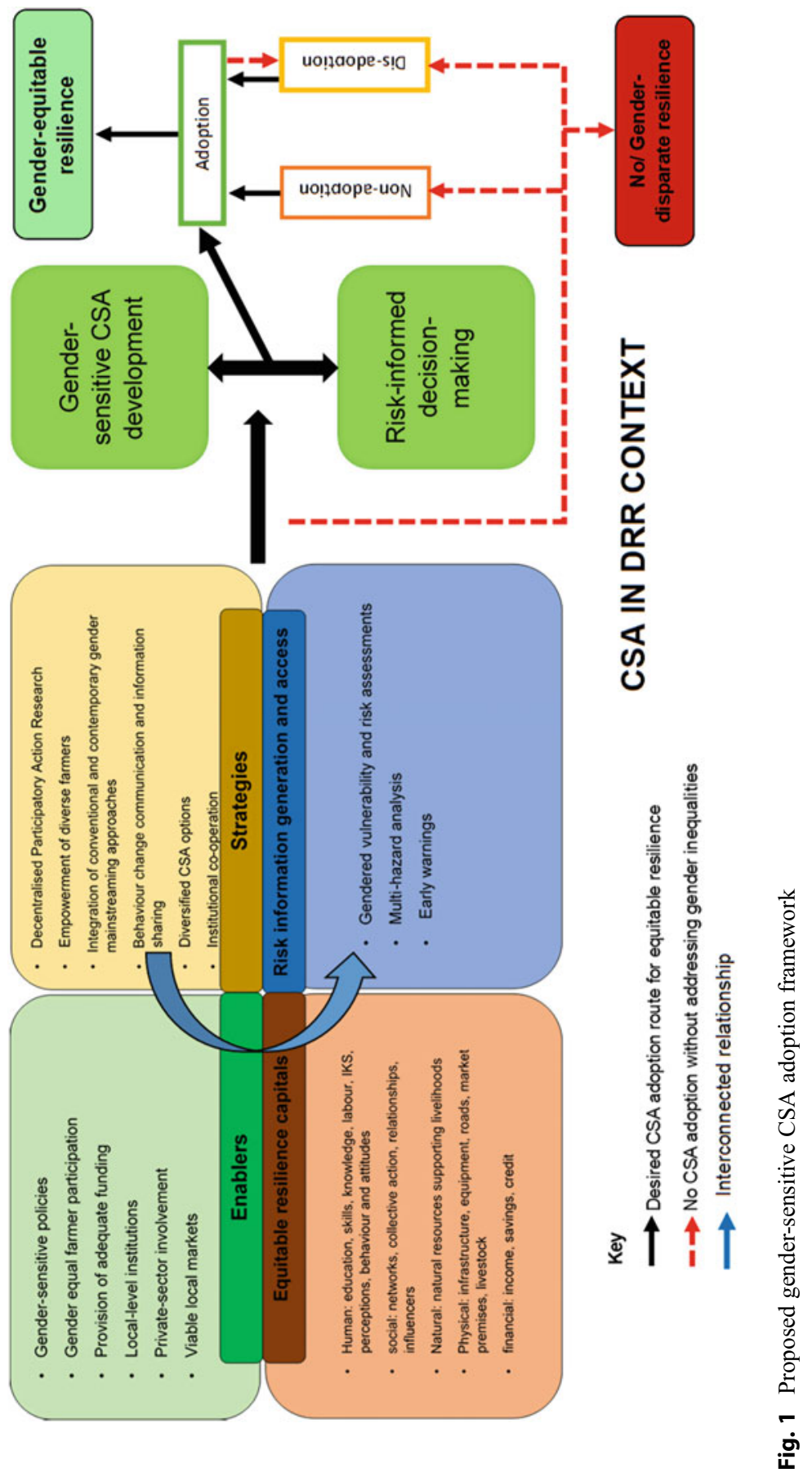


equality and address gendered vulnerability, which should potentially result in improved CSA adoption at household level. The gender-sensitive CSA adoption framework comprises various interconnected components that should be used from a gender perspective throughout, aimed at transformation toward more egalitarianresilient societies. In the proposed framework, the desired adoption route likely to help achieve gender-equitable resilience is illustrated with black arrows, and the undesired route likely to result if gender disparities are not addressed is shown with red dotted arrows. The blue curved arrow shows that the enablers, strategies, gender equality, and risk information are all interconnected, interacting to inform gendersensitive technology development and risk-informed decision-making. The framework components are discussed in the following subsections.

\section{Enablers for CSA Adoption}

\section{Gender-Sensitive Policies}

The findings of this study show that there are preexisting gender inequalities at household level which may be perpetuated by gender-blind CSA implementation. This chapter suggests that an improvement in CSA adoption by women farmers would require gender-sensitive policies to ensure that issues of gender inequality are addressed to achieve gender parity. This requires a holistic assessment of CSA that will consider implementation strategies and resilience capitals, not just limited to the technological benefits of CSA. There is need for policies directly or indirectly linked to CSA to be assessed for their implications on different genders. This should include land tenure systems, marriage and property inheritance laws, technology development, as well as economic empowerment, which all affect CSA adoption decisions (Doss et al. 2015; Khoza et al. 2019).

\section{Gender-Equal Farmer Participation}

CSA presents various opportunities where farmers should be engaged for active participation in CSA technology development. However, study findings showed that currently, farmers' participation in CSA is mainly as recipients of already developed technologies and CSA information. CSA is characterized by top-down approaches which may fail to pay attention to critical gender issues that hinder adoption. This study reiterates the need for CSA implementation to ensure equal participation of farmers in technology development and identification of CSA options to adequately meet the resilience needs of diverse farmer categories. There should also be gender-equal participation in the co-creation of knowledge through research in gendered risk assessments, vulnerability assessments, and multi-hazard analysis. Gender-equal participation of farmers will likely assist with the identification of gender-differentiated barriers of CSA adoption and opportunities that can be harnessed to improve adoption across different genders.

When smallholder farmers are given equal opportunities to participate in various aspects of CSA, this is likely to also bring to the fore critical contextual gender issues 
and to facilitate transformation. Gender-equal participation may potentially enable bottom-up engagement in CSA, where farmers can also contribute their knowledge and experiences. This is especially important when considering the role of indigenous knowledge systems in CSA. Ultimately, equal participation of farmers allows CSA to engage with their various realities, ensuring farmers have a voice in the design and ownership of CSA projects and technologies. When farmers are given the space to participate in various components of CSA, not just as recipients, they are more likely to adopt CSA. This will also enhance sustainability of CSA in communities.

\section{Provision of Adequate Funding}

There is no doubt that technological requirements of CSA are likely to be costly and beyond the reach of many individual farming households. For instance, capital investment for some CSA options, such as irrigation schemes and aquaculture, may be costly. This means that at a higher national and global scale, there is a need to improve funding for CSA projects. This can be achieved through multiple funding streams. For example, at a national level, countries should fulfil commitments of the Malabo Declaration that states that African governments should allocate $10 \%$ of their public spending to agriculture (AU 2014). Other funding sources could be explored through other government sectors. For instance, on the basis of its relationship with DRR, disaster risk management (DRM) departments could also provide part of the funding required for CSA. Similarly, at a global level, multiple sources may be explored apart from specific CSA projects, such as resilience-building, climate change adaptation, or DRR funds.

Importantly, CSA funding should ensure that funds provided address the resource needs of local-level institutions, such as the provision of vehicles, information and communication technology equipment, and recruitment of more extension agents. This will likely improve quality of gender-specific contact extension services provided to the farmers. This may also compel strategic direction toward the integration of local-level institutions.

\section{Local-Level Institutions}

Strong operational relationships among local government and nongovernmental institutions are required to facilitate gender-sensitive CSA adoption. According to Carpenter et al. (2012), polycentricity is key to resilience, often helping to promote connectivity within systems and facilitating learning. This is key in CSA where diverse institutions need to work together. These institutions are the first-level responders to different hazards affecting smallholder farmers; hence, their cooperation is necessary to improve adoption of diverse CSA options. Locallevel institutional cooperation and collective action remain essential in the provision of extension services, information dissemination, and facilitation of gender transformation in communities. Ultimately, a polycentric approach enhances the delivery of CSA with precision and efficiency to meet gender-specific farmer resilience needs. 


\section{Private Sector and Viable Markets}

The findings reveal that one major drawback of CSA adoption by both men and women farmers is the lack of improved quality of life as a result. This was connected to a lack of economic opportunities, resulting in farmers failing to earn meaningful income from the sale of surplus produce. This chapter recommends that innovative strategies be implemented to involve the private sector in CSA to ensure win-win scenarios for farmers and business. CSA adoption is negatively affected by unviable local markets, and an enabling environment for CSA adoption should consider creation of viable local markets where farmers can buy and sell CSA inputs and outputs. This may help create a thriving local economy and increase the income earned from CSA to meet household needs.

\section{Strategies to Improve CSA Adoption}

\section{Decentralized Participatory Action Research}

The gender disparities identified in the study magnify the need for CSA adoption to be informed by participatory action research (PAR), which can be achieved with an enabling environment for gender-equal participation of smallholder farmers. PAR may facilitate engagement with farmers, giving them a platform to share their experiences in gender issues that demotivate them from adopting CSA or drive them to discontinue CSA. Furthermore, PAR should be decentralized, allowing research to be conducted at the local epicenter of climate disasters. The strength of PAR in driving CSA adoption is the recognition of farmers as both sources and consumers of knowledge, with their involvement in research tapping into local knowledge, perspectives, and realities. At the same time, they are able to use the information from PAR to inform their CSA adoption decisions. Decentralization of PAR to local level should be gender-sensitive, identifying best ways to examine challenges and opportunities for specific groups of farmers in CSA. Farmer participation will illuminate sociopsychological behaviors, attitudes, and perceptions of diverse groups, ensuring that precise and complete information equips farmers' decision-making. PAR is also essential in creating a platform for behavior change communication and information sharing.

\section{Diversity of Livelihoods and CSA Options}

Considering CSA from a resilience perspective magnifies the need for CSA to move beyond dominance of conservation farming as revealed in this study. If CSA is to contribute to resilience of diverse smallholder farmers, then there is a need to provide diversified CSA options in addition to conservation farming. Diversified CSA options ensure redundancy so that in the face of a climate-related disaster affecting one component of the farming systems, farmers have other alternatives to rely on (Carpenter et al. 2012). The dominant focus on conservation farming could help explain protracted food insecurity and vulnerability, with farmers often relying on food aid assistance. Therefore, a resilience lens in CSA advocates for transformation 
toward consideration of other livelihoods and CSA options. This may include income generation through sale of improved livestock breeds, honey from apiculture, or fish from aquaculture, among others. Diversity and redundancy should improve the resilience of farmers, and gender should be considered to assess which CSA options would be relevant to each category of farmers.

\section{Empowerment of Diverse Women Farmers}

In view of the study findings, this chapter accentuates the need for the empowerment of communities in general and women in particular to equip them to be able to articulate their resilience needs and to demand more space to participate in different aspects of CSA. The heterogeneity of women smallholder farmers is suggestive of their corresponding diverse resilience needs. This is essential when considering issues of economic empowerment in CSA. CSA adopters have not been able to derive tangible economic benefits, yet this is one of the goals of CSA. Empowerment of farmers means they will participate in technology development, contributing toward defining relevant CSA options they need, and they will participate in decision-making at various levels from intra-household level going up.

Empowerment in CSA should ensure that women farmers can share their experiences, practice autonomy and agency, and be able to collectively come together to tackle structural bottlenecks affecting their adoption decisions. However, this requires a transformation from traditional gender mainstreaming approaches that have shaped empowerment efforts in the past, toward an integrated approach that also considers contemporary approaches such as intersectionality, African feminisms, and positive masculinity (Arndt 2002; Davis 2008). Studies have shown insufficiencies of traditional gender mainstreaming approaches in addressing gender inequality and patriarchy in agriculture (Khoza et al. 2019). The integration of traditional and contemporary approaches may compensate for the weaknesses of each approach applied on its own. Empowerment should address practical gender needs while also ensuring that attention is paid to structural gender issues that may hinder especially women household heads from adoption of CSA. Empowerment should also pave way for participation and inclusion of farmers, especially women, in the various aspects of CSA as explained in earlier sections. This remains an essential vehicle of transformation.

\section{Gender-Equitable Resilience Capitals}

Based on the study findings, this chapter highlights that a resilience framing of CSA adoption compels consideration of gender inequality and gendered vulnerability with regard to access to and control and ownership of resilience capitals (Mayunga 2007). The gender constructions that determine who owns, has access, and controls resilience capitals should be assessed in CSA as they shape farmers' adoption decisions. In order to achieve resilience-building through CSA, there is a need for deliberate strategies aimed at establishing gender equality and equity in the ownership, control of, and access to social, natural, physical, financial, and human 
resilience capitals. This will require CSA to engage with disparities and to improve especially the ownership of resilience capitals such as farming equipment, livestock, land, and finance by women farmers. This will not only enable them to cope with climatic disturbances but will also ensure they are equipped to build back better or bounce forward from each disturbance. Paying attention to resilience capitals also helps illuminate key vulnerability issues that dispose farmers to either dis-adoption or non-adoption of CSA. Creating gender equality and equity in resilience capital ownership will require innovation in tackling the socioculturally entrenched patriarchal systems and women's subordination, and contemporary gender mainstreaming approaches may be useful in this regard.

While addressing identified gender inequality issues may not be the primary mandate of agricultural departments, a resilience framing emphasizes polycentricity and collective action. Other development actors need to be involved in CSA, such as gender, DRM and community development departments, NGOs, women's rights activists, and local leaders. These structures already exist at a local level, although agriculture departments may need to lead the integration to ensure that the expertise of various groups is channeled toward addressing inequality and vulnerability in pursuit of resilience.

\section{Risk Information: Generation and Access}

Any attempt to improve CSA adoption requires strategies to ensure supply of adequate information to aid farmers during decision-making. Collective action, participation, and inclusion are key to the generation of risk information. Processes to generate risk information are undertaken by governments, NGOs, and donor agencies in many countries. These are usually in the form of vulnerability and risk assessments, as well as hazard analysis. However, there is a need to move beyond simple gender-disaggregated data generated in these processes to critically engage with the gender implications of collected data in terms of resilience-building. Risk information is not only useful to technocrats and practitioners, but farmers should also have access to the information for decision-making. Knowledge is required to make informed decisions. Across different gender groups, its creation and acquisition is important in decision-making. The proposed framework advocates for the involvement of farmers in knowledge co-creation, which will harness valuable indigenous knowledge, especially with regard to climate hazards and early warnings. This means attention should be paid to access to gender-sensitive risk communication. Gender-sensitive risk information is also requisite in development of gendersensitive CSA technologies.

A systemic approach helps appreciate that CSA adoption decisions are not only based on technological benefits of CSA options. Farmers consider other risks that affect their resilience capitals negatively or positively within the wider system context. For instance, for many communities, disease epidemics such as HIV/ AIDS remain a health risk that threatens agricultural labor provision in households. Therefore, any adoption improvement strategy should engage farmers to identify 
what other risks they face in their contexts, and this may be achieved through gender vulnerability and risk assessments, as well as multi-hazard analyses that should endeavor to obtain in-depth qualitative perspectives on systemic risks.

\section{Risk-Informed Decision-Making}

Adoption decisions of men and women smallholder farmers are influenced by various factors depending on their gender roles (Khoza et al. 2019). Importantly, decision-making for men and women household heads should be viewed within the multifaceted context in which decisions are made and have to be risk-informed. There is a need to acknowledge different factors and drivers that shape decisionmaking for different genders. A resilience framing of CSA accommodates riskinformed decision-making (RIDM) even at smallholder farmer level (Weichselgartner and Pigeon 2015). RIDM acknowledges that decision-making is not in simple linear fashion as traditionally understood. It is a more comprehensive analytical approach that interrogates and seeks to understand complex interactions between people, risks, hazards, and systems. Risk-informed decisions pay attention to qualitative information from gender-differentiated risk assessments (Gardoni et al. 2016), narratives, and realities that shape decisions by different farmers. However, Apostolakis (2004) caution against the exclusive use of risk assessments to inform decisions, necessitating a more consolidated approach where gender vulnerability assessments and multi-hazard analyses can also feed into decision-making.

\section{Gender-Sensitive CSA Technology Development}

Findings of this study showed that smallholder farmers, irrespective of gender, were not directly involved in the development of CSA technologies. Rather, technology development was a top-down process where farmers were viewed as recipients. However, this chapter argues that if CSA adoption is to be improved, there is a need for farmers to participate in technology development. CSA technology development should be two-way, with provision for consideration and development of local farmer innovations for further scaling up. Development and dissemination of CSA technology should be participatory to generate and manage perspectives that may determine adoption decisions made especially by the women farmers. CSA technology development should therefore be informed by the gender analyses that recognize gender roles and interactions with technology in relation to culture, behaviors, attitudes, and social influences (Ngigi et al. 2018; Khoza et al. 2019). Development of CSA technology should appreciate and address any underlying disparate distribution of resilience capitals. Failure to consider these underlying factors and corresponding strategies to address them may manifest as low adoption of CSA by women farmers.

Additionally, through gender analyses, CSA technology development can consider existing and projected changes in gender roles. CSA technology may seek to 
improve current gender roles, or transform them, depending on identified inequalities and farmer needs (Nyasimi and Huyer 2017), where technologies can be developed to help bridge the gender productivity gap and contribute to equitable resilience across the heterogeneity of smallholder farmers. For instance, women in men-headed households and women who were household heads lamented labor demands of basin conservation farming which they felt increased their workload, while they have other reproductive and community roles too. Moreover, caution should be exercised to ensure that CSA does not reinforce gender stereotypes, for instance, when CSA projects target women only for energy-saving stove distribution.

Critical to gender-sensitive technology development is the cost of CSA technologies. Women who are already less economically empowered than men are less likely to be able to afford costly new CSA technologies. CSA focus should also be on women's economic empowerment. Ultimately, rural women need appropriate CSA technologies that can transform their contexts and realities where necessary, helping them to become more resilient. This can be achieved by engaging the diverse groups of women to establish their practical and structural gender needs. Gendersensitive CSA technology development should be as pragmatic and transformative as possible in pursuit of resilience.

\section{Operationalization of the Framework}

This chapter suggests that utilitarian value of the framework lies in its ability to identify and confront issues of inequality and social disparities in a broader context, which may pave way for decision-making that favors CSA adoption by smallholder farmers. Operationalization of this framework should start at a district level and bring together communities and experts from diverse disciplines such as agriculture, DRM, climate change, gender, community development, local leaders, businesses, weather services, research institutions, and NGOs. Most of these disciplines are already represented at district level, although there is a need to transition toward collective integrated operations. The agriculture department may maintain the leadership and coordinating mandate, ensuring representation and multidirectional participatory engagement, communication, and information dissemination. The use of the framework can then feed into large-scale administrative processes at the provincial and national levels. Some components of the framework are already addressed by ongoing activities, such as vulnerability assessments and hazard and risk assessments. However, a gender lens should be applied in these processes, which should include smallholder farmers in their diversity, and findings from assessments should be used to inform all DRR components, not just for response through humanitarian food assistance.

The proposed framework is worth exploring as it derives value from the participatory nature of its formulation and has a strong focus on social dimensions in CSA adoption. As such, it addresses some of the gaps in current appreciation of CSA adoption, which seems to elevate the technological merits of CSA at the expense of 
the equally important social dimensions. This framework's ingenuity also lies in that it speaks to the insufficiencies of a linear approach to CSA. Challenges may arise in that the framework was developed independent of any existing CSA project, which means that its uptake by different institutions is not guaranteed. Nevertheless, it does present a normative approach to improving CSA adoption so that men and women smallholder farmers can be enabled to "build back better equally, leaving no-one behind," which should form the core of resilience and sustainable livelihood outcomes in Africa.

\section{Key Lessons, Study Limitations, and Future Research Prospects for CSA}

Several key lessons can be drawn from this study that applied a resilience framing to the interrogation of gender dimensions in CSA adoption. Firstly, at local level where loss and damage from each disaster event worsen food insecurity and poverty, there is an amplified urgency for gender-equitable resilience-building through CSA. This compels improvement of CSA adoption by at-risk smallholder farmers. Drawing on resilience principles may give strategy direction in CSA implementation at the local level. Resilience principles such as the maintenance of redundancy and diversity, management of intra-system connectivity, feedbacks, promotion of social learning, participation and inclusion, embracing polycentricity, and understanding that agricultural systems are complex adaptive systems all play an essential role in pursuit of gender-equitable resilience in CSA.

Secondly, there remains need to address gender inequality as it stands in the way of CSA adoption and inhibits the successful pursuit of resilience. Areas of focus should include the promotion of active and equal participation of smallholder farmers, especially vulnerable, at-risk women in CSA technology development. CSA technologies should not merely be developed for the smallholder farmers, but with them, creating space for consideration of their innovations and indigenous knowledge systems to suit their gender-specific resilience needs.

Lastly, it is essential to shift from risk-based decision-making toward riskinformed decision-making, starting at household level right up to institutional level where CSA support is provided. This is dependent on an appreciation of the fact that CSA adoption decision-making is not linear and only based on the technological benefits of CSA in the face of climate change, but rather occurs within a multifaceted decision-making context, which may differ along gender lines.

Further studies on CSA can adapt and replicate the study methodology in similar developmental contexts and disaster profiles. This study did not test the applicability of the proposed gender-sensitive CSA adoption framework. Future studies can test the applicability of the proposed framework in any of the Southern African countries or in other developing regions. The key is sensitivity to site-specific contexts on issues of gender, inequality, power, and agency. CSA adoption itself is a difficult variable to assess by means of a cross-sectional survey. Longitudinal studies can be considered in future research. 


\section{Conclusions}

The assessment of the gender dimensions of CSA adoption by smallholder farmers anchored in resilience thinking enriches understanding of the inherent challenges specifically faced by women farmers. The study highlights several factors that drive gender-differentiated vulnerability and contribute to low CSA adoption by at-risk women farmers. These factors include gender disparities in ownership of resilience capitals, limited participation of farmers in CSA technology development, narrow CSA options that can be adopted by farmers, and the limited tangible benefits realized from CSA. There is a need to improve the adoption of CSA by diverse smallholder farmers and to meet their gender-specific resilience requirements in the face of climate-related disasters. This can be achieved through the creation of an enabling environment and implementation of strategies that can facilitate gendersensitive CSA technology development and the equal participation of smallholder farmers. The farmers should be assisted to make risk-informed decisions by improving generation and access to risk information through participatory action research. Gender equity and equality in the ownership of resilience capitals can contribute to gender-equitable resilience in smallholder farming. In conclusion, this study reiterates the importance of a gendered approach to CSA to improve adoption by smallholder farmers who directly interface with inclement climate hazards.

\section{References}

African Union (AU) (2014) Implementation strategy and roadmap to achieve the 2025 vision on CAADP. African Union, Addis Ababa

Apostolakis GE (2004) How useful is quantitative risk assessment? Risk Anal 24(3):515-520

Arndt S (2002) Perspectives on African feminism: defining and classifying African-feminist literatures. Agenda 17(54):31-44

Arslan A, Asfaw S, Cavatassi R, Lipper L, McCarthy N, Kokwe M, Phiri G (2018) Diversification as part of a CSA strategy: the cases of Zambia and Malawi. In: Lipper L, McCarthy N, Zilberman D, Asfaw S Branca G (eds) Climate smart agriculture: building resilience to climate change. Springer, Cham

Asfaw S, Bishop-Sambrook C, Diei Y, Firmian I, Henninger N, Heumesser C, Huyer S, Kristjanson P, Lefter C, Lehel S (2015) Gender in climate-smart agriculture: module 18 for gender in agriculture sourcebook. World Bank Group, Washington, DC

Béné C, Headey D, Haddad L, von Grebmer K (2016) Is resilience a useful concept in the context of food security and nutrition programmes? Some conceptual and practical considerations. Food Sec 8(1):123-138

Bennett E, Carpenter S, Gordon L, Ramankutty N, Balvanera P, Campbell B, Cramer W, Foley J, Folke C, Karlberg L (2014) Toward a more resilient agriculture. Solutions 5(5):65-75

Carpenter S, Arrow K, Barrett S, Biggs R, Brock W, Crépin A-S, Engström G, Folke C, Hughes T, Kautsky N (2012) General resilience to cope with extreme events. Sustainability 4(12):32483259

Chandra A, McNamara KE, Dargusch P (2017a) Climate-smart agriculture: perspectives and framings. Clim Pol 18(4):1-16

Chandra A, McNamara KE, Dargusch P (2017b) The relevance of political ecology perspectives for smallholder climate-smart agriculture: a review. J Polit Ecol 24(1):821-842

Coetzee C, Van Niekerk D, Raju E (2016) Disaster resilience and complex adaptive systems theory: finding common grounds for risk reduction. Disaster Prev Manag 25(2):196-211 
Collins A (2017) Saying all the right things? Gendered discourse in climate-smart agriculture. J Peasant Stud 45(1):1-17

Davis K (2008) Intersectionality as buzzword: a sociology of science perspective on what makes a feminist theory successful. Fem Theory $9(1): 67-85$

Diao X, Hazell P, Thurlow J (2010) The role of agriculture in African development. World Dev 38 (10):1375-1383

Doss C, Kovarik C, Peterman A, Quisumbing A, van den Bold M (2015) Gender inequalities in ownership and control of land in Africa: myth and reality. Agric Econ 46(3):403-434

Ensor J, Forrester J, Matin N (2018) Bringing rights into resilience: revealing complexities of climate risks and social conflict. Disasters 42(2):287-305

Food and Agriculture Organisation (FAO) (2013) Climate-smart agriculture sourcebook. FAO, Rome

Gardoni P, Murphy C, Rowell A (2016) Risk analysis of natural hazards: interdisciplinary challenges and integrated solutions: risk analysis of natural hazards. Springer, Cham

Glover D, Sumberg J, Ton G, Andersson J, Badstue L (2019) Rethinking technological change in smallholder agriculture. Outlook Agric 48(3):169-180

Khoza S, Van Niekerk D, Nemakonde LD (2019) Understanding gender dimensions of climatesmart agriculture adoption in disaster-prone smallholder farming communities in Malawi and Zambia. Disaster Prev Manag 28(5):530-547

Kpadonou RAB, Owiyo T, Barbier B, Denton F, Rutabingwa F, Kiema A (2017) Advancing climate-smart-agriculture in developing drylands: joint analysis of the adoption of multiple on-farm soil and water conservation technologies in West African Sahel. Land Use Policy 61:196-207

Lipper L, Thornton P, Campbell BM, Baedeker T, Braimoh A, Bwalya M, Caron P, Cattaneo A, Garrity D, Henry K (2014) Climate-smart agriculture for food security. Nat Clim Chang 4 (12):1068-1072

Lipper L, McCarthy N, Zilberman D, Asfaw S, Branca G (2018) Climate smart agriculture: building resilience to climate change. Springer, Cham

Manyena B, O'Brien G, O'Keefe P, Rose J (2011) Disaster resilience: a bounce back or bounce forward ability? Local Environ 16(5):417-424

Matin N, Forrester J, Ensor J (2018) What is equitable resilience? World Dev 109(9):197-205

Mayunga JS (2007) Understanding and applying the concept of community disaster resilience: a capital-based approach. In: Summer academy for social vulnerability and resilience building, Munich

Müller C, Waha K, Bondeau A, Heinke J (2014) Hotspots of climate change impacts in subSaharan Africa and implications for adaptation and development. Glob Chang Biol 20 (8):2505-2517

Murray U, Gebremedhin Z, Brychkova G, Spillane C (2016) Smallholder-farmers and climate smart agriculture: technology and labor-productivity constraints amongst women smallholders in Malawi. Gend Technol Dev 20(2):117-148

Ngigi MW, Müller U, Birner R (2018) Farmers' intrinsic values for adopting climate-smart practices in Kenya: empirical evidence from a means-end chain analysis. Clim Dev 10 (7):614-624

Nhamo L, Mabhaudhi T, Modi A (2019) Preparedness or repeated short-term relief aid? Building drought resilience through early warning in Southern Africa. Water SA 45(1):75-85

Nyasimi M, Huyer S (2017) Closing the gender gap in agriculture under climate change. Agric Dev $5(30): 37-40$

Nyasimi M, Kimeli P, Sayula G, Radeny M, Kinyangi J, Mungai C (2017) Adoption and dissemination pathways for climate-smart agriculture technologies and practices for climate-resilient livelihoods in Lushoto, Northeast Tanzania. Climate 5(3):1-22

Speranza CI, Wiesmann U, Rist S (2014) An indicator framework for assessing livelihood resilience in the context of social-ecological dynamics. Glob Environ Chang 28(9):109-119

Taylor M (2018) Climate-smart agriculture: what is it good for? J Peasant Stud 45(1):89-107

Teddlie C, Tashakkori A (2009) Foundations of mixed methods research: integrating quantitative and qualitative approaches in the social and behavioral sciences. Sage, Thousand Oaks 
Walker B, Holling CS, Carpenter S, Kinzig A (2004) Resilience, adaptability and transformability in social-ecological systems. Ecol Soc 9(2):1-9

Weichselgartner J, Pigeon P (2015) The role of knowledge in disaster risk reduction. Int J Disaster Risk Sci 6(2):107-116

Williams TO, Mul ML, Cofie OO, Kinyangi J, Zougmoré RB, Wamukoya G, Nyasimi M, Mapfumo P, Speranza CI, Amwata D (2015) Climate smart agriculture in the african context. In: Feeding Africa: an action plan for African agricultural transformation. African Development Bank, Dakar

Open Access This chapter is licensed under the terms of the Creative Commons Attribution 4.0 International License (http://creativecommons.org/licenses/by/4.0/), which permits use, sharing, adaptation, distribution and reproduction in any medium or format, as long as you give appropriate credit to the original author(s) and the source, provide a link to the Creative Commons license and indicate if changes were made.

The images or other third party material in this chapter are included in the chapter's Creative Commons license, unless indicated otherwise in a credit line to the material. If material is not included in the chapter's Creative Commons license and your intended use is not permitted by statutory regulation or exceeds the permitted use, you will need to obtain permission directly from the copyright holder.

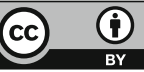

